Todorova, M. (2016). Interpreting conflict mediation in Kosovo and Macedonia. Linguistica Antverpiensia, New Series: Themes in Translation Studies, 15, 227-240.

\title{
Interpreting conflict mediation in Kosovo and Macedonia
}

\author{
Marija Todorova \\ Hong Kong Baptist University, SAR Hong Kong \\ marija.todorova@gmail.com
}

While the basic role of interpreters is to facilitate communication, situations of conflict mediation and third party intervention very often surpass the usual role and skills needed by interpreters in any other situations. Interpreters in conflict mediation need to be more sensitive to the background situation, emotions, and need to be able to sense perceptions and feelings. They also need to help the mediator create trust, open communication channels, and understand cultural differences and emotions. Drawing on Touval's (2002) influential argument that biased mediators in international disputes are often the most effective, as well as Kriesberg's (1991) concept of the quasi-mediator, this paper looks at the role of interpreters in conflict mediation, with a particular focus on the issue of their prescribed or perceived neutrality, based on a survey of interpreters and mediators involved in conflict mediation processes in Kosovo and Macedonia. The concept of neutrality is revisited in terms of conflict mediation theory as well as interpreting theory. Recommendations are provided for training in mediation for interpreters.

\section{Introduction}

Both conflict and interpreting are nowadays studied from an interdisciplinary perspective: researchers of conflict look at it from a range of different disciplines, including communication studies, peace studies and applied linguistics; whereas interpreting is examined through the combined lenses of applied translation studies, linguistics, neuropsychology, and sociology. However, research in these two fields tends to exist in parallel, rarely making exchanges across the theoretical and empirical divides. This paper aims to address this by providing an overview of the key points of intersection in the theoretical concepts of peace studies and of interpreting studies, with a special focus on conflict mediation where the two meet, especially through the application of the concept of the quasi-mediator, as developed in the field of mediation studies by Kriesberg (1991). In terms of real-world data sources and applicability of this attempt to connect conflict resolution and interpreting, this research is primarily informed by the author's own experience as an interpreter during the conflicts in Kosovo and Macedonia in the late 1990s and early $2000 \mathrm{~s}$. 
Today, an increasing number of scholars (Apter, 2005; Baker, 2010; Dragovic-Drouet, 2007; Inghilleri, 2005; Palmer, 2007; Rafael, 2007; Stahuljak, 2000) are investigating the role of interpreters in processing military data, facilitating communication between armies, the local population, and the media, or investigating war prisoners. This paper tries to tap into the practices and opinions of interpreters who have been actively involved in situations of conflict, especially conflict mediation. The aim of the paper is to contribute to the acknowledgement and promotion of the particular role translators and interpreters play as active factors in the resolution of conflicts through mediation. Interpreters influence the mediation process during a conflict through the use of language, and understanding the situation and perception of the views and values of the parties in the mediation process.

\section{Historical overview}

The history of war and peace negotiations in the region of Western Balkans has been closely related to the role of interpreters, who had worked alongside great historical figures in political and diplomatic affairs in attempts to resolve violent conflicts. During the Ottoman Empire (1420 c.), whose European domain included the Balkans, interpreters called dragomans were important figures in the diplomatic relations between the Sultan and 'Western' ambassadors, serving "much more that the diplomatic secretaries", and usually keeping this 'title' in the family for many generations (Berridge, 2009, pp. 49-50). One such dragoman, Antonio Crutta, of Albanian origin, who worked for the Polish king Stanislav-Auguste, served as an interpreter during the negotiations between Russia and Turkey in 1792, with Poland as the neutral mediator (Roland, 1999, p. 50).

The importance of translators and interpreters became especially significant in more recent crises, such as the 1990s conflicts in the former Yugoslavia, which witnessed a change in the perception of the interpreter's role: from a language carrier to a necessary partner in the intercultural dialogue and a co-creator of interaction and a partner in the development of the new environment. During the war in Bosnia and Herzegovina (BiH), the most protracted and deadly of the wars that tore apart the former federation of Yugoslavia, UN peacekeepers were deployed to secure the cease-fire. Their mission required wide-ranging interaction with the local communities necessitating extensive language support. Local interpreters were employed in every UNPROFOR office, and many of them were never trained to be interpreters, but had other professions, "such as the doctor who worked as an interpreter for the British general Michael Rose ... and a remarkable number were engineering students and/or the children of engineers" (Baker, 2010, p. 158). 
Later involvements of interpreters in conflict mediation in the former Yugoslavia include the conflicts in Kosovo and Macedonia. These two conflicts were very much connected. During the Kosovo conflict Albanian and Roma refugees leaving Kosovo took temporary refuge in Macedonia. The Kosovo crisis of 1998/1999 ended with UN Security Council Resolution 1244, a result of the peace negotiations between Serbian and Kosovar Albanian representatives facilitated by the international community represented by Martti Ahtisaari. In Macedonia, EU representative Francois Leotard and USA representative James Pardew (previously involved in the brokering of the Dayton peace agreement in Bosnia), together with official and unofficial leaders from the country signed the Ohrid Framework Agreement, putting an end to the violent conflict between the Macedonian and Albanian communities in 2001. In both conflict situations, the two conflicting communities spoke different languages (Albanian/Serbian and Albanian/Macedonian, respectively). And in both cases the third party brought in either the English or the French language as the language of mediation. This needs to be highlighted as an important difference between the Kosovo/Macedonia and the earlier Croatia/Bosnia mediations: these language pairs are not mutually intelligible and the resourcing of language services was therefore more complex.

During the conflict mediation process in Macedonia, the international facilitators Pardew and Leotard had separate meetings with Albanian and Macedonian ethnic party representatives, as well as with experts appointed by the country's president. On one side were the Macedonian and Albanian negotiators, while opposite them were the international facilitators with their advisers and interpreters. A joint official meeting between Macedonia's authorities and the representatives of the Albanian and Macedonian parties with the international facilitators in Ohrid happened only during the first day of the negotiations and twice during the negotiations, where procedural issues were discussed. Whenever a compromise was near for an issue or a formulation that could be acceptable to both ethnic sides, the international facilitators would gather the two sides, and in the end both of them either agreed or did not. Then, separate talks were carried out through mediation for other issues (Ljatifi, 2008, pp. 47-48).

\section{Conflict mediation and neutrality}

Mediation offers an effective way of bringing the antagonized sides together. It is an intervention of a mediator, a person possessing the necessary skills while remaining impartial, designed to reach a mutually acceptable solution to a problem at the center of the conflict between the sides. As such, mediation is a peaceful, non-compulsory and non-binding approach to conflict management, where the involved parties willingly 
participate whilst retaining their control over the agreed terms the entire time. Mediation is especially important for long-term, deeply rooted conflicts, because such conflicts are rarely settled without outside assistance. Mediation can be defined as "an act of intervention between two sides in order to create a relationship between them, to be able to influence it" (O'Sullivan, Hartley, Saunders, Montgomery, \& Fiske, 1998, p. 176). Jacob Bercovitch (1996) defines mediation as a form of conflict solving that includes an outside party; a third side that is not directly involved in the discussion. Unlike arbitration, where there is a third party leading the activity, mediation and reconciliation are voluntary procedures encompassing various forms of assistance, but without court or legal procedures. In this way, mediation assists the sides in the conflict to reach a mutually acceptable solution. According to the Berghof Research Center for Constructive Conflict Management (Fisher, 2001), mediation is a political process where the parties involved (or key participants) in the international or ethno-political conflict accept one or more third parties which are not part of the conflict, which are trusted by all the sides in the conflict and are regarded as potential supporters in the process of overcoming the deadlock in the conflict. Mediation can be official or unofficial. Official mediation rests on a mediator's mandate, an agreed program, participation rules, etc.

Interventions are divided into two groups. The interventions from Track 1 consist mostly of negotiations and mediation after an open violent conflict, leading to an agreement to put an end to violence. As a process, it usually aimed at finding a political solution together with the legitimate and de facto leaders. While being result-oriented, it also seeks to change the opinions of the main actors in the negotiations. Unofficial mediation involves Track 2 interventions, such as initiating dialogue, organizing workshops aimed at problem solving, as well as employing mediation on a local level facilitated by internal mediators. As can be seen from the above examples, the two intervention tracks are not only complementary in practice, but also often interchangeable. This is due to the fact that mediation can be influenced by tensions, interests and mutual clashes by factions within the negotiating parties themselves.

The role of the mediator starts by creating conditions conducive of opening and sustaining communication channels between the sides, helping them to focus on the core issue(s), and generating opportunities to address their interests or needs in an attempt to resolve the conflict. The mediator encourages the sides to come up with a solution primarily on their own. Although at times the mediator may propose ideas and suggestions, and even put forth formal proposals and solutions, the mediator primarily aids the sides to define the agenda, to define and redefine problems, to communicate more effectively, to discover a common way of thought and to reach an agreement. Successful mediation results in an agreement accepted and recognized by the sides. 
When we speak of mediation, one issue that is continuously raised is the mediator's neutrality, whether the mediator should give suggestions, and what types of strategies are appropriate to be used in the mediation process. Gulliver (1979), who complains of the lack of interest from other disciplines in the mediator's role, criticizes the stereotypical image of an unbiased mediator whose only role is helping the involved parties to cooperate toward a mutual goal instead of competing against each other, when in practice the mediator actually plays a much more active role: "I doubt that it is rare to meet a truly uninterested, unbiased mediator. He can be completely unbiased toward both sides, but be completely biased toward his own interests, sometimes at the expense of one of the sides in the conflict" (pp. 30-31). Based on the examples from the Middle East and the Balkans, Saadia Touval concludes that impartiality and neutrality are not as important as power (Touval, 2002). Zartman and Touval (1996) state that "if the acceptance of mediation is based on the estimate of gain, then the assumption that mediators can be impartial should be revised" (p. 451). In their view, if the mediator already has good relations with one of the involved parties, that could actually contribute to promoting effective communication and assist in the formulation of helpful proposals. For them, even the opposing site would be able to perceive this position of the mediator as beneficial: they would regard it as evidence of the mediator's ability to put pressure on the other side and force it to come to an agreement. The authors conclude that mediators don't have to be impartial in order to be accepted by the parties or be effective in their efforts: "Mediators should show that they are interested in achieving a result that is acceptable to both sides and they shouldn't be biased so much that they prevent such a result to be achieved" (Zartman \& Touval, 1996, p. 452).

Zartman and Touval also discuss three ethical dilemmas that arise during mediation in international conflicts. One, mediators may often feel pressured to primarily address the short-term objective of stopping the immediate violence at the expense of the long-term goals to resolve the conflict. Two, mediators can be faced with a choice between achieving "the possible solution which breaks international norms or $[\ldots]$ the solution which is consistent with the principles of justice accepted by the international community" (Zartman \& Touval, 1996, p. 459). And lastly, mediation helps to reach a solution to the conflict, but it does not secure conciliation and it doesn't always remove the causes of the conflict. Mediators should continue their involvement even after the agreement has been reached, during its implementation, by keeping the parties responsible towards what they had agreed to.

Louis Kriesberg (1991) introduces the term quasi-mediator, namely somebody who is not meant to be a mediator, and can even belong to one of the sides in the conflict, "who are not official representatives, but are connected with official representatives and function as their agents" (p. 23). This in fact is exactly what the role of the interpreter consists of, as I will attempt to demonstrate later on. Quasi-mediators are less restricted by the 
social role of an official mediator and can help build the supporting framework for peace:

By showing flexibility, they raise expectation among the other side that the de-escalation initiative will be accepted. Furthermore, they can suggest how such initiatives can be articulated so that they will be credible and effective. And lastly, they can guarantee that even risky de-escalation initiatives will not be misused. (Kriesberg, 1991, p. 25)

Quasi-mediators can be very effective in the early stages of de-escalation because, despite not having the resources available to a formal mediator, they can be a useful addition, even a basic tool in situations where the formal mediator is not accepted. In cases of difficult conflicts on a larger scale, formal mediators have a key role after the sides in the conflict reach a situation where they are close to a de-escalation agreement, while quasimediators play a key role in encouraging the sides in a conflict to reach these positions through inspection, suggestions and information that return the trust between both sides in the conflict. The cultural links and connections that may exist between the quasi-mediator and one or both of the sides in the conflict can help the mediation process by increasing the acceptance of the mediator and increasing the belief that the mediator can bring compromise and an agreement. Furthermore, as mentioned earlier, the mediator who is perceived as being closer to one side than the other can actually prove to be more effective in the mediation process, in particular when the mediator acts in a balanced way. Support for this view can be found not only in anecdotal evidence, but also in data produced by laboratory research on mediation (Carnevale \& Choi, 2000). This chalenges the long-established "wisdom" about the prescribed neutrality of mediators, but also of interpreters involved in mediation processes. Rather then being an impediment, their perceived closeness to one side in the conflict can actually prove to be a productive and desirable circumstance.

\section{The interpreter as a quasi-mediator}

Historical developments in the field of interpreting, especially after the Second World War, have put to the fore questions of ethics and liability, applying to both professional and nonprofessional interpreters. This research attempts to identify the position of interpreters in the conflict mediation process through self-reflective insight from professionally active translators/interpreters with some experience of interpreting in a conflict situation and conflict mediation in Macedonian and/or Kosovo. The role of interpreters in mediation very closely resembles that of a quasi-mediator, as explained by Kriesberg (1991), belonging to one side of the conflict, thus increasing the acceptance of the mediator, and increasing the chances 
for reaching an acceptable solution. However, to perform this task most effectively the interpreters need to be trained substantially in the process of mediation.

In order to assess the self-perception of conflict interpreters in terms of their perceived place in the mediation process, as well as gauge their capacity and needs for mediation skills, a web survey was conducted with 86 self-selected professional interpreters from two post-conflict locations (73 from Macedonia and 13 from Kosovo). The respondents were identified through personal contacts, direct or indirect, and included persons of diverse backgrounds in terms of gender, age, ethnicity, spoken language, etc. The findings of the survey conducted with professional interpreters working in Macedonia and Kosovo were thereafter confirmed and expanded upon with life-story interviews conducted with two interpreting experts (IEs). These two interpreting experts had been involved in high-level negotiation and mediation talks and directly present in Track 1 mediation events during the mediation talks to bring to an end the violent conflict in Macedonia in 2001, namely the July/August 2001 negotiation talks held in Ohrid involving four political leaders from the country (two ethnic Macedonian and two ethnic Albanian) and two international mediators. Both interpreting experts have reportedly been brought up in multilingual environments since their early childhood, and both have passed much of their childhood and youth living abroad. They are also two of the first official interpreters in Macedonia, with significant working experience. What adds to their social status is their engagement as university lecturers, a position which is highly respected in the Macedonian society. In terms of their language skills, both interpreters have Macedonian as a native language. Their additional language skills include English and French. To protect their identity due to the sensitiveness of their involvement in the peace process, acronyms will be used instead of their names.

In order to understand the opinions and attitudes from the other side of the communication process, a similar life-story interview, although in a shorter and more targeted form, was conducted with two international mediators (MEs), who had been directly involved in official and unofficial mediation during violent conflicts. The two MEs come from different countries of origin, speak different languages as native and have different career paths. They have over 15 years each of international experience in the sphere of diplomacy. They have both spent time in Macedonia, and one of them was directly involved in the Kumanovo mediation process to put an end of the violence in Kosovo. In the course of their work as mediators both had used interpreters, although in the absence of any previous training on how to communicate using an interpreter. ${ }^{1}$ One of the most important aspects of interpreting in conflict mediation raised in both survey and interviews are the questions regarding the interpreters' invisibility, neutrality and trustworthiness. 
The professional high-level interpreters, as well as the users of their services, seem to support the point made by Angelelli (2004), namely that the myth of invisibility of the interpreters appears to be real. Although interpreting studies scholars have recognized not only the visibility of the interpreter but have also demonstrated the interpreter's agency, this has still not filtered through the practice of conflict mediation, or for that matter, international diplomatic practice in general. In conflict studies in general, the view of the mediation process seems to be power-driven and highly exclusive in terms of its focus on power-brokers (the mediator/s) while the interpreters are still perceived as largely powerless.

Despite their somewhat similar experience in terms of language acquisition and development of interpreting skills, the two interviewed interpreters in this research had a distinctly different position about interpreters' visibility. IE2 strongly supported the view that interpreters, especially in political discussions, should stay invisible and neutral, based on her experience as conflict mediation interpreter, because in this way the interpreter "is offered protection from any kind of responsibility.

This myth is not only real but also transferred to new generations of interpreters through the education process. This is confirmed by the survey, where $73 \%$ of respondents thought that interpreters should remain invisible. Only $4 \%$ of the respondents thought that the interpreter should be visible. On the other hand, about $60 \%$ of respondents agreed that the role of the interpreter was 'always' or 'often' crucial in the mediation process during conflict, almost to the extent that they "can contribute to quickier and more relaxed (a flow of information) mediation."

IE1 agreed that the interpreter should be seen as invisible, because "sometimes when she becomes too visible, the parties in the negotiations speak with her. But even in such situations, it is required of the interpreter, to transfer communication during informal time or during a break" (IE1, personal communication, 9 April 2012). According to IE1, "the interpreter has a role even during breaks; on a higher political level this is less present, but on a lower level interpreters can act as a bridge between the parties, and help mend their relations" (IE1, personal communication, 9 April 2012). Similarly, IE2 would "sometimes give my personal opinion outside of the negotiations in private conversations" (IE2, personal communication, 12 April 2012). Furthermore, IE1 highlighted an important aspect of the interpreter's job, i.e. the fact that interpreters are very often asked for their opinions on the issues related to the mediation by their employers. This is when the skills of an interpreter extend well beyond mere linguistic competencies: "In such situations, the interpreter must be open-minded in order to understand the situation and her own position in the given situation. The interpreter should have an understanding and accept different opinions" (IE1, personal communication, 9 April 2012). This is not unlike the role of a quasi-mediators who "provide information about the adversaries' thinking and concerns and they may provide ideas about new options for waging and resolving a conflict" (Kriesberg, 2012). 
Interpreters, although not recognized as mediators, frequently are used to pass on information from one side (usually the one they belong to) to the mediator. This role as a go-between is very often experienced by interpreters who work for the international, external mediator in a conflict.

Similar to the reconsideration of neutrality in academic discourses on mediation, in the interpreting field this too this has been one of the recent points of contention both in scholarly works as well as among practitioners. Standardly imposed and presupposed, neutrality as a normative category related to the work and conduct of interpreters is now increasingly seen to be at odds with their actual behavior and practices in the performing of their duties in the field. The notion of the interpreter as a neutral processing and transmitting unit of linguistic meaning from the source into the target speech has been challenged as a mere myth by recent empirical studies in the field. This new evidence has sought to avoid the simplifications of the mechanistic model of interpreting, instead arguing for a new vision of interpreters as always already culturally situated, as not only transmitting but also actively mediating and constructing the communicated meaning, in particular in interpreting situations involving a smaller number of participants in the dialogue. Another blow to the perceived/prescribed disinterestedness of interpreters is seen in the fact that interpreters are aware of the purpose of the communication they are brokering, and are thus potentially interested in its course and outcomes. In the interviews, both interpreters reflected on the notion of faithfulness, agreeing that interpreters should maintain their faithfulness to the information they receive. IE2 went on to explain that: "The interpreter must be loyal to the speaker and to the information" (IE2, personal communication, April 2012). For ME2, "the loyalty of the interpreter should rest with their personal level of professionalism and credibility as an interpreter" (ME2, personal communication, 15 January 2013).

Trustworthiness was another important characteristic of interpreters in mediation mainly raised as an issue by the MEs, as either something interpreters reportedly lacked (according to ME1), or in terms of valuing the work and contribution of interpreters as indispensable in performing the tasks of international mediation as "interpreters allow for trust to be built and relationships developed over the medium term", making possible the "art of diplomacy and international negotiations" (ME2, personal communication, 15 January 2013). When asked what is the best quality that an interpreter can bring to the positive mediation meeting, ME2 identified trust among the people present at the meeting. This includes not only trust between the mediator and the interpreter, but also between the interpreter and the other parties involved in the mediation process since "it is vital that all the parties to the conversation are able to trust each other and not feel that the contents of a private conversation will be relayed to outside parties" (ME2, personal communication, 15 January 2013). Additionally, trust is also built through long-term professional cooperation, not only with the international mediator, but also with the interlocutors, or other parties in 
the mediation process. This notion was mentioned by both professional interpreters who were interviewed, and it was also raised as crucial by the mediators. They confirmed that "being able to use the same interpreter helps build a professional relationship" (ME2, personal communication, 15 January 2013). This point of stability in the working relationship was also echoed by the interpreters: "Interpreting would be better in the process of mediation if the same interpreter was present at the event from beginning to end" (IE2, personal communication, 12 April 2012). Similarly to the characteristic of the quasi-mediator, the interpreter "can help overcome mistrust within their own side by conveying their belief in the sincerity and trustworthiness of the opposing side" (Kriesberg, 2012).

In terms of improving their performance as interpreters in a conflict mediation process, the interpreters expressed the need for receiving more specialized training in mediation. Although they both possessed bilingual/bicultural skills, they considered becoming interpreters as something that they learned through experience rather than formal training. They commented that their interpreting training took place on the job, stating they had learned from their own mistakes, although neither of the two specified what those mistakes had been. This is understandable having in mind that even on a global level interpreting is a fairly recently established profession, and in Macedonia interpreter training was established only after the conflict in 2001. Being expert-practitioners in the area of interpreting, it is not surprising that both of the interviewed interpreters became interpreter trainers. Their opinions and attitudes towards interpreting acquired through their professional experience will thus influence future interpreters working in the Macedonian context. Speaking from personal experience, IE1 expressed doubt over the level of preparedness of interpreter graduates to work in crisis situations, in particular as they didn't receive any training in "negotiation and mediation processes" (IE1, personal communication, 9 April 2012). She also acknowledged that she had no mediation training herself, but was certain that it would have been of great use in her job. Similarly in the interpreter survey, although $67 \%$ of the respondents said that they need mediation knowledge and skills in order to do their job, only $15 \%$ of the total number of respondents had previously attended any mediation training. However, twice as many (30\%) answered that they had attended conflict management training and almost the same number of respondents (33\%) had attended intercultural communications training. It is interesting that one of the respondents answered in the open description field that they had acquired the mediation knowledge and skills by "having interpreted in various events dedicated to that particular topic".

Context-relevant communication skills were ranked as very important by the mediators and the interpreters alike. In ME1's opinion, the most important skill of an interpreter was knowledge of communications skills, especially knowledge of diplomatic protocol or "how to talk to diplomats and everyone else". This opinion corresponds 
with the views expressed by the two interviewed professional interpreters who stressed that for Track 1 conflict mediation it was of high importance for the interpreter to be acquainted with the protocol, i.e. to know the formal and informal procedures for communication and behavior in events of such level and character. Furthermore, it was stressed that interpreters in conflict mediation work in multicultural environments, thus they require skills that go well beyond the linguistic competences. ME2 agreed that interpreters have influence over the mediation process, by providing "linguistic meaning and cultural insights for those less familiar with a particular situation or country. External mediators might not understand cultural cues or linguistic nuances that could have either a positive or negative effect on a particular negotiation" (ME2, personal communication, 15 January 2013). The mediators interviewed in this research both agreed on the necessity for interpreters to be equipped with intercultural understanding, meaning understanding of the culture(s) of all parties in the mediation process. For ME2:

Being able to accurately interpret verbal and non-verbal cues (such as body language) would allow them [interpreters] to let people know if the approach they are taking is having a positive or negative impact on the discussion. I appreciate this is a fine line and could lead to accusations or suggestions of them not being impartial. However, if the language being used is wholly negative or unconstructive, then it is better that this is known sooner rather than being allowed to continue, to the cost of the conflict mediation process as a whole (ME2, personal communication, 15 January 2013).

\section{Conclusion}

Neutrality as a trait and behavior displayed by both mediators and interprets during conflict situations, while historically often prescribed and desired as a means to gain the trust of all parties involved, has recently been problematized to the extent that conflict researchers now argue that biased mediators, or mediators that are trusted more by one side in the conflict, can actually contribute more to the effective resolution of the conflict. While some scholars have sought to relativize neutrality as meaning that conflict mediators should strive to encourage all sides in the conflict to tell their story while not passing judgment, others argue that not only is neutrality impossible, but its opposite may actually be a more effective approach to conflict resolution. The same case for reconsideration of neutrality can be made for conflict interpreters as well, the perception of which is now changing from mere linguistic machines to human agents inhabiting a complex web of cultural positions who perform a quasimediator role in conflict resolution. Similar to mediators, interpreters are 
also involved in creating and maintaining a relationship of trust in the conflict mediation setting. In that relationship of trust, interpreters have to position themselves in relation to both the mediator(s) as well as the conflict parties, which entangles them in a more complex set of relations than the mediators, who are primarily focused on the conflicting parties. This already complex matrix of trust relations inhabited by the interpreters of conflict situations is only complicated further by the fact that they are not outsiders to the conflict, like the mediators, but are from the onset positioned well inside the conflict situation and one (or more) of the parties to that conflict.

In terms of the interaction between conflict mediators and interpreters, as well as their perceptions of the other's role in the conflict mediation process, this research has revealed that mediation experts have different positions on the use of interpreters in high-level mediation talks, especially in conflict situations. However, apart from providing interpretation during meetings, most of their activities involve establishing a sense of trust and providing encouragement to the parties involved to reach an acceptable solution, and thus resemble the role of a quasimediator. What proved to be the most important skill of interpreters in mediation processes from the viewpoint of mediators was trustworthiness. One of the interviewed high-level mediators even went as far as to proclaim that he didn't trust interpreters in conflict situations. Being able to trust the interpreter and establishing a relationship with the interpreter was underscored as a factor that makes the work of the mediator more effective.

Having said this, it is important to note that neither of the mediators mentioned the visibility of the interpreter as problematic. For them it seems that interpreters are part of the mediation team, as visible as anyone else, and it is expected that they act in that manner and with all the professionalism. It can be deduced that the mediators see the interpreter as their close colleagues, who shares the same goals and same professional etiquette.

The fact that most interpreters in the study believed interpreters should remain invisible could be indicative of a growing disconnect between professional practice and conceptual research. On the other hand, there is a clear contradiction at play in their self-reported position: most interpreters believed that interpreters should indeed remain invisible yet at the same time most also believed the interpreter did have a crucial role to play in conflict mediation. That would indicate that while they may be intuitively aware of their agency in the mediation process, the dominant education narrative still works to cancel that out.

In their self-reflective narratives, the interpreters agreed that one factor that could improve the outcome of the interpretation process in conflict mediation was better communication between the mediators and the interpreters, in particular as "the job involves no previous preparation, cooperation, and contact with the parties involved" (IE1, personal communication, 9 April 2012). 
Both the interpreters and the mediators highlighted the importance of intercultural communication competence in the conflict mediation interpreting process. It would seem that this aspect of the work of the interpreter is even more important for the mediators: both mediators mentioned that interpreters should develop trust among all parties in the mediation process, which assumes developing trust with people belonging to different cultural backgrounds.

This point was also reflected in the results of the survey with professional interpreters. Although most respondents reported they had an undergraduate degree in translation and interpreting, while a significant number held a master degree in translation and/or interpreting, most indicated there were other skills that they needed but had not acquired during their formal education process. Although training in interpretation is obviously important for interpreters during conflict situations, other types of training are also equally (or even to a greater extent) necessary when working in a mediation situation. This fact is often overlooked by interpreters themselves and by the organizations recruiting them. Training in mediation (or even joint training alongside mediators) would be highly useful for interpreters, as it would empower them to contribute more fully to the mediation process as quasi-mediators, as well as to utilize their agency during the mediation process in a more conscious and purposeful way, with the ultimate aim of doing their utmost to help both the mediators and the mediated parties to reach an agreement and a resolution to the conflict.

\section{References}

Angelelli, V. C. (2004). Revisiting the interpreter's role. Amsterdam: John Benjamins. Apter, E. (2005). The translation zone: A new comparative literature. Princeton, NJ: Princeton University Press.

Baker, M. (2010). Interpreters and translators in the war zone: Narrated and narrators. The Translator, 16(2), 197-222.

Bercovich, J. (Ed.). (1996). Resolving international conflicts: The theory and practice of mediation. Boulder, CO: Lynne Reinner.

Berridge, G. R. (2009). British diplomacy in Turkey, 1583 to the present: A study in the evolution of the resident embassy. Leiden: Martinus Nijhoff.

Carnevale P. J., \& Dong-Won Choi. (2000). Culture in the mediation of international disputes. International Journal of Psychology, 35(2), 105-110.

Dragovic-Drouet, M. (2007). The practice of translation and interpreting during the conflicts in the Former Yugoslavia (1991-1999). In M. Salama-Carr (Ed.), Translating and interpreting conflict (pp. 29-40). Amsterdam: Rodopi.

Fisher, R. J. (2001). Methods of third-party interventions. Berlin: Berghof Research Center for Constructive Conflict Management. Available at www.berghofhandbook.net. 
Gulliver, P. H. (1979). Disputes and negotiations: A cross-cultural perspective. New York: Academic Press.

Inghilleri, M. (2005). Mediating zones of uncertainty: Interpreter agency, the interpreting habitus and political asylum adjudication. The Translator, 11(1), $69-85$.

Kriesberg, L. (1991). Formal and quasi-mediators in international disputes: An exploratory analysis. Journal of Peace Research, 28(1), 19-27.

Kriesberg, L. (2012). Mediation in conflict systems. Systems Research and Behavioral Science, 29, 149-162.

Latifi, V. (2008). Negotiations to Achieve the Ohrid Agreement. Skopje: Open Society Institute. [Љатифи, В. (2008). Преговорите за постигнување на Охридскиот Договор. Скопје: Институт отворено општество ].

O’Sullivan, T., Hartley, J., Saunders, D., Montgomery, M., \& Fiske, J. (1998). Key concepts in communication and cultural studies. London: Routledge.

Palmer, J. (2007). Interpreting and translation for western media in Iraq. In M. SalamaCarr (Ed.), Translating and interpreting conflict (pp. 13-28). Amsterdam: Rodopi.

Rafael, V. (2007). Translation in wartime. Public Culture, 19(2), 239-246.

Roland, R. (1999). Interpreters as diplomats: A diplomatic history of the role of interpreters in world politics. Ottawa: University of Ottawa Press.

Stahuljak, Z. (2000). Violent distortions: Bearing witness to the task of wartime. TTR: Traduction, Terminologie, Rédaction, 13(1), 137-151.

Touval, S. (2002). Mediation in the Yugoslav Wars: The critical years. London: Palgrave Macmillan.

Zartman, W., \& S. Touval. (1996). International mediation in the post-Cold War era. In C. Crocker, F. Hampson, \& P. Aall (Eds.), Managing global chaos (pp. 445461). Washington, DC: United States Institute of Peace.

1 The interviews and the survey were conducted in Macedonian and English depending on the situation and the language used by the respondents. For those conducted in Macedonian, all materials used in this article have been translated by the author. 